\title{
Parameterized Principal - Agent Game of Third Party Logistics and Randomization of Its Mixed Nash Equilibrium Strategies
}

\author{
Yicheng Gong ${ }^{1, *}$, Yanna Zhang ${ }^{1}$, Li Yu ${ }^{1}$, Juan Zhao ${ }^{1}$, Qingqing $\mathrm{Li}^{2}$ and Jieyi Chen ${ }^{1}$ \\ ${ }^{1}$ Wuhan University of Science and Technology, Wuhan 430065, China \\ ${ }^{2}$ Huazhong University of Science and Technology, Wuhan 430074, China \\ *Corresponding author
}

\begin{abstract}
This article aims to improve the practice feasibility of game theory for logistics demand enterprises and the third party logistics enterprises in a principal-agent game. Firstly, some parameters are introduced to the game. Especially the complaint rate is used to depict the degree of positive work or negative work. Secondly, strategies are digitalized. Lastly, Monte Carlo (MC) simulation is adopted to randomize the players' strategies according to the probability distribution of a mixed Nash equilibrium. The mixed equilibrium distribution of the logistics game is $((0.3333,0.6667),(0.4097,0.5903))$. Theoretically, the logistics demand enterprises (D) expect to select supervision and indulgence as the probability 0.3333 and 0.6667 respectively. And the third party logistics enterprises (S) expect to select positive effort and negative effort as the probability 0.4097 and 0.5903 respectively. The simulation results show that the randomizing coincides with the probability distribution of the Nash equilibrium above $97.18 \%$.
\end{abstract}

Keywords- the third party logistics; principal-agent game; mixed Nash equilibrium; Monte Carlo simulation

\section{INTRODUCTION}

With the progress of science and technology, enterprises are breaking the constraints of traditional time and space in the 21 st century. Because only few enterprises have self-logistics, logistics outsourcing and third-party logistics vigorously developed. As in [1], Fortune Weekly reported that about $60 \%$ of the top 500 US companies have signed a third-party logistics contract. To win the market advantages, companies need to improve the efficiency of resource allocation and establish cooperative relationship with suppliers. However, the third party logistics enterprises sometimes do not provide high quality services in order to minimize their cost. Logistics demand enterprises often find it is difficult to supervise the third party logistics enterprises due to information asymmetry.

Some scholars utilized game theory to research third-party logistics. J.X. Liu established an asymmetric information principal-agent game between the logistics demand enterprises and the third party enterprises as in [2]. As in [3] J. Wang researched the European Union national agricultural products logistics electronic supply chain, and then put forward China's agricultural products logistics e-commerce supply chain network structure and operation mechanism. As in [4] Y.S. Qiao introduced two parameters into principal-agent model with both symmetric information and asymmetric information. In 2014, A. Aguezzoul Based on 67 papers from 1994 to 2013 summarizes the third-party logistics proposing 11 key criteria for the selection of third-party logistics as in [5]. Principalagent mechanism research incentive contract design and analysis of the information disadvantage of the entrusting party how to stimulate the information advantage of the agent to choose their own actions in line with their interests as in [6].

The scholars discussed the principal-agent models form different perspectives. Most of them make qualitative analysis of proposed policy and theoretical Nash equilibrium. But a mixed Nash equilibrium is theoretically a probability distribution on the strategy space of the game. How to help enterprises randomize their strategies according to the mixed Nash equilibrium, it is still open. This paper tries to utilize the Monte Carlo simulation (MC) to provide a randomizing guidance for the logistics demand enterprises and third party enterprises. Before doing it, we digitalize game strategies as convenience and set up a principal -agent game model, to which some parameters are introduced to depict the behavior uncertainty.

\section{PRINCIPAL - Agent GAMe ANALysis OF ThIRD PARTY LOGISTICS COOPERATION}

\section{A. Principal - Agent Game Model}

With great development of production forces and largescale production, principal-agent relationship is produced. Principal-agent theory studies that someone hires others to service for them, then they pay the corresponding remuneration to others according to the quantity and quality of service. Here someone is referred to principal, and others are referred to agent. The agent has relative advantage with over principal.

Principal-agent theory is established in asymmetric information which means some participant have more information than others. And in the principal-agent game model, principal's utility function is not as the same as agent's. However, the principal pursues their great fortune. The agent wants to have both income and leisure best. This makes a conflict of interest. Thus principal need do some incentive measures or supervision for agent. 


\section{B. Principal - Agent Game of the Third Party Logistics}

This paper studies the principal-agent game model between the logistics demand enterprises (D) and the third party logistics enterprises (S). In the principal-agent game model, the third party logistics enterprises (S) may work positively or negatively. And logistics demand enterprises (D) may supervise (S) or indulgence $(\mathrm{S})$. This is the typical game between the principals and agents.

For representing (S) and (D)'s payoff under different situations, let $\mathrm{Q}$ is the total investment amount and $\mathrm{P}$ is the total payoff. And $m$ and $n$ are the input allocation ration of the logistics demand enterprises (D) and the third party logistics enterprises (S) respectively, where $m+n=1$. (D) and (S)'s investment are Qm and Qn respectively. In this paper complaint rate is used to describe the degree of positive work and native work. In the website of the State Post Bureau of The People's Republic of China, there are effective complaint rates of the main logistics enterprises in February 2017. Let $\mathrm{h}$ is the value of the difference of the biggest complaint rate and (D)' complaint rate, then $\mathrm{h}$ divided by range of complaint rate which uses $\mathrm{k}$ to represent this. And $\mathrm{k}$ is the the degree of effort. Thus total payoff is $(1+\mathrm{k}) \mathrm{P}$ if $(\mathrm{S})$ works positively. And $(1-\mathrm{k}) \mathrm{P}$ is the total payoff under negative effort. Correspondingly $(1+\mathrm{k}) \mathrm{Pm}$ and $(1+\mathrm{k}) \mathrm{Pn}$ are respectively (D)'s and (S)'s total payoff in the positive effort. Due to (S)'s behaviors, the logistics demand enterprises (D) may supervise (S). Suppose the cost of supervision is c. If (S) work positively, the logistics demand enterprises (D) reward $\mathrm{kb}$ to (S), otherwise, (D) deducts $\mathrm{kb}$ from $(\mathrm{S})$. Degree of the reward and punishment is related to the degree of positive work and native work. In (D)'s utility function, (D) wants to have free time in their work time. Utility of free time can be described by their wages, using $u$ to denote leisure income, it is also related to $\mathrm{k}$. If (S) works negatively, (S) will get ku for its leisure income.

The payoff of (D) is (1+k)Pm-Qm-c-kb and (S)'s payoff is $(1+\mathrm{k}) \mathrm{Pn}+\mathrm{kb}-\mathrm{Qn}-\mathrm{ku}$, if (D) supervises (S), (S) works positively. The payoff of (D) is (1-k)Pm-Qm and (S)'s payoff is (1-k)Pn$\mathrm{Qn}+\mathrm{ku}$, if (D) indulgences (S), (S) works negatively.

We can get a principal-agent game model between the logistics demand enterprises (D) and the third party logistics enterprises (S). The game matrix is shown as Table 1 .

TABLE I. PRINCIPAL -AGENT GAME OF THE THIRD PARTY LOGISTICS

\begin{tabular}{|c|c|c|c|}
\hline & \multirow{2}{*}{ Payoff } & \multicolumn{2}{|c|}{ (S) } \\
\hline & & Positive efforts & Negative efforts \\
\hline \multirow{2}{*}{ (D) } & Supervision & $\begin{array}{l}(1+\mathrm{k}) \mathrm{Pm}-\mathrm{Qm}-\mathrm{c}-\mathrm{kb}, \\
(1+\mathrm{k}) \mathrm{Pn}+\mathrm{kb}-\mathrm{Qn}-\mathrm{ku}\end{array}$ & $\begin{array}{l}(1-k) P m+k b-Q m-c, \\
(1-k) P n-Q n-k b+k u\end{array}$ \\
\hline & Indulgence & $\begin{array}{l}(1+\mathrm{k}) \mathrm{Pm}-\mathrm{Qm}, \\
(1+\mathrm{k}) \mathrm{Pn}-\mathrm{Qn}-\mathrm{ku}\end{array}$ & $\begin{array}{l}\text { (1-k)Pm-Qm, } \\
(1-k) P n-Q n+k u\end{array}$ \\
\hline
\end{tabular}

According to the scribe method, there is no pure strategy Nash Equilibrium. And there is no Pareto Dominating Equilibrium for the logistics demand enterprises (D) and the third party logistics enterprises (S) respectively. By game theory, there must be a mixed Nash equilibrium for this game model. Suppose that the probability of the logistics demand enterprises (D) supervision is $\mathrm{p}$, indulgence correspondingly is 1-p. The probability of the third party logistics enterprises (S) positive effort is q, correspondingly the negative efforts probability is 1-q. The logistics demand enterprises (D)'s expected return is (1).

$$
\begin{gathered}
\mathrm{E}_{\mathrm{D}}=\mathrm{p}[\mathrm{q}((1+\mathrm{k}) \mathrm{Pm}-\mathrm{Qm}-\mathrm{c}-\mathrm{kb})+(1-\mathrm{q})((1-\mathrm{k}) \mathrm{Pm}-\mathrm{Qm}-\mathrm{c}+\mathrm{kb})]+(1- \\
\mathrm{p})[\mathrm{q}((1+\mathrm{k}) \mathrm{Pm}-\mathrm{Qm})+(1-\mathrm{q})((1-\mathrm{k}) \mathrm{Pm}-\mathrm{Qm})]=-2 \mathrm{pqkb}+\mathrm{pkb}- \\
\mathrm{pc}+2 \mathrm{qkPm}+(1-\mathrm{k}) \mathrm{Pm}-\mathrm{Qm}
\end{gathered}
$$

By maximize principle, let the first partial derivative of $E_{D}$ about $\mathrm{p}$ is zero. From (2), q is solved in (3).

$$
\begin{gathered}
\partial \mathrm{E}_{\mathrm{D}} / \partial \mathrm{p}=-2 \mathrm{qkb}+\mathrm{kb}-\mathrm{c}=0 \\
\mathrm{q}=(\mathrm{kb}-\mathrm{c}) / 2 \mathrm{~kb} \quad 1-\mathrm{q}=(\mathrm{kb}+\mathrm{c}) / 2 \mathrm{~kb} \quad(\mathrm{~kb}>\mathrm{c})
\end{gathered}
$$

The (S)'s mixed strategy is $((\mathrm{kb}-\mathrm{c}) / 2 \mathrm{~kb},(\mathrm{~kb}+\mathrm{c}) / 2 \mathrm{~kb})$, where $\mathrm{kb}>\mathrm{c}$. This shows the probability of (S)'s positive effort is related to punishment, cost of (D)'s supervision and the degree of (S)'s effort. Meanwhile the reward or punishment must bigger than the supervision cost. The higher probability of (S) work positively increases with the reward and the degree of effort.

Similarly third party logistics enterprises (S)'s expected return is (4).

$$
\begin{array}{r}
E_{S}=q[p((1+k) P n+k b-Q n-k u)+(1-p)((1+k) P n-Q n-k u)]+(1- \\
q)[p((1-k) P n-Q n-k b+k u)+(1-p)((1-k) P n-Q n+k u)] \\
=2 q p k b+2 q k P n-2 q k u-p k b+(1-k) P n-Q n+k u
\end{array}
$$

By the maximal principle, let the first partial derivative of $E_{S}$ about $q$ is zero. From (5), $p$ is solved in (6).

$$
\partial \mathrm{E}_{\mathrm{S}} / \partial \mathrm{q}=2 \mathrm{pkb}+2 \mathrm{kPn}-2 \mathrm{ku}=0
$$

$$
\mathrm{p}=(\mathrm{u}-\mathrm{Pn}) / \mathrm{b} \quad 1-\mathrm{p}=(\mathrm{b}-\mathrm{u}+\mathrm{Pn}) / \mathrm{b} \quad(\mathrm{u}>\mathrm{Pn}, \mathrm{b}>\mathrm{u}-\mathrm{Pn})
$$

The (D)'s mixed strategy is $((\mathrm{u}-\mathrm{Pn}) / \mathrm{b},(\mathrm{b}-\mathrm{u}+\mathrm{Pn}) / \mathrm{b})$, where $\mathrm{u}>\mathrm{Pn}$ and $\mathrm{b}>\mathrm{u}-\mathrm{Pn}$. If (S)'s payoff of free time is bigger, the probability of (D) supervision is higher. The punishment or reward is very important in principal-agent game, because the strategies of both side of the game are related to it.

In summary, the mixed Nash equilibrium of table 1 is $(((\mathrm{kb}-$ c) $/ 2 \mathrm{~kb},(\mathrm{~kb}+\mathrm{c}) / 2 \mathrm{~kb}),((\mathrm{u}-\mathrm{Pn}) / \mathrm{b},(\mathrm{b}-\mathrm{u}+\mathrm{Pn}) / \mathrm{b}))$. As any mixed Nash equilibrium is a probability distribution on the strategy space in theory. But, it is difficult for enterprises to randomize their strategies according to the probability distribution in practice.

\section{RANDOMIZING PRINCIPLE OF MiXEd EQUILIBRIUM STRATEGIES}

\section{A. Introduction to Monte Carlo Simulation (MC)}

Monte Carlo method is a random statistical sampling 
method. Its main idea is to use the frequency to approximate the corresponding probability. As in [7], the earliest Monte Carlo experiments date back to the famous Buffon random needle cast in the 18th century. Since the Monte Carlo method can simulate realistically the actual physical process, it has many applications.

In this paper, both logistics demand enterprises and third party logistics enterprises have exactly two behavior strategies. In order to randomize cooperation strategies later by Matlab, we digitalize strategies as the next part.

\section{B. The Digitalizing of Cooperation Strategies}

For convenience, two strategies of the logistics demand enterprises (D) are supervision and indulgence, which can be respectively digitalized into 1 and 0 . These digitalized strategies are very easy to understood, where 0 is referred to as indulgence and 1 is referred to as supervision. Thus, the distribution of Nash equilibrium can be converted into two two-point discrete random strategies variable $\mathrm{X}_{\mathrm{D}}$ and $\mathrm{X}_{\mathrm{S}}$ whose distribution laws are shown in Table 2 and Table 3

From Table 2, $\mathrm{X}_{\mathrm{D}}$ has the same probability distribution as the logistics demand enterprises (D) are expected by the mixed Nash equilibrium $\left(\left(\mathrm{p}_{1}, \mathrm{p}_{2}\right),\left(\mathrm{q}_{1}, \mathrm{q}_{2}\right)\right)$. If (D) randomly select strategies just according to the random samples of variable $X_{D}$, then (D) selects supervision and indulgence respectively at the probability $\mathrm{p}_{1}$, and $\mathrm{p}_{2}$. Therefore $\mathrm{X}_{\mathrm{D}}$ can be called the strategy variable of the enterprises (D).

Similarly, from Table $3, \mathrm{X}_{\mathrm{S}}$ has the probability distribution as the third party logistics enterprises $(\mathrm{S})$ are expected by the mixed Nash equilibrium $\left(\left(\mathrm{p}_{1}, \mathrm{p}_{2}\right),\left(\mathrm{q}_{1}, \mathrm{q}_{2}\right)\right)$, which expects $(\mathrm{S})$ select positive efforts and negative efforts respectively with the probability $\mathrm{q}_{1}$ and $\mathrm{q}_{2}$. If $(\mathrm{S})$ randomly select strategies just according to the random samples of variable $X_{S}$, then $(S)$ selects positive efforts and negative efforts respectively at the probability $\mathrm{q}_{1}$ and $\mathrm{q}_{2}$. Therefore $\mathrm{X}_{\mathrm{S}}$ can be called the strategy variable of the third party logistics enterprises.

\section{Randomizing the Strategies on Distributions of $X_{D}$ and $X_{S}$}

Take randomizing demand enterprises's strategies as an example. It means to randomly sample a two point discrete random variable $\mathrm{X}_{D}$ whose distribution law is shown in Table 2. The random sample of $\mathrm{X}_{D}$ can be done as three steps.

Step 1.r=rand. It get a random sample from the uniform distribution in the interval $(0,1)$.

TABLE II. RANDOM VARIABLE OF LOGISTICS DEMAND ENTERPRISE $\mathrm{X}_{\mathrm{D}}$

\begin{tabular}{|l|c|c|}
\hline & \multicolumn{2}{|c|}{ Value of The Digitalized D's Strategy } \\
\hline Strategises & 1 & 0 \\
\hline Probability & $\mathrm{p}_{1}$ & $\mathrm{p}_{2}$ \\
\hline
\end{tabular}

TABLE III. RANDOM VARIABLE OF LOGISTICS DEMAND ENTERPRISE $\mathrm{X}_{\mathrm{S}}$

\begin{tabular}{|l|c|c|}
\hline & \multicolumn{2}{|c|}{ Value of The Digitalized S's Strategy } \\
\hline Strategises & $\mathbf{1}$ & $\mathbf{0}$ \\
\hline Probability & $\mathrm{q}_{1}$ & $\mathrm{q}_{2}$ \\
\hline
\end{tabular}

Step 2. Set $\mathrm{p}^{(1)}=\mathrm{p}_{1}, \mathrm{p}^{(2)}=\mathrm{p}_{1}+\mathrm{p}_{2}=1$. If $0<\mathrm{r}<\mathrm{p}^{(1)}, \mathrm{X}_{\mathrm{D}}=1$; If $\mathrm{p}^{(1)}<\mathrm{r}<\mathrm{p}^{(2)}, \mathrm{X}_{\mathrm{D}}=0$.

Step 3. Go to Step1, repeat till you get enough samples.

It can be proven the random sample $\mathrm{R}$ which is get by the above 3 steps methods obeys the same distribution law as $\mathrm{X}_{\mathrm{A}}$.

Notice that $\mathrm{P}\left(0<\mathrm{R}<\mathrm{p}^{(1)}\right)=\mathrm{p}^{(1)}-0=\mathrm{p}_{1}-0=\mathrm{p}_{1}=\mathrm{P}(\mathrm{X}=1)$, and $\mathrm{P}\left(\mathrm{p}^{(1)}<\mathrm{R}<\mathrm{p}^{(2)}\right)=\mathrm{p}^{(2)}-\mathrm{p}^{(1)}=\mathrm{p}_{2}=\mathrm{P}(\mathrm{X}=0)$.

It is shown that the probability of events $\{0<\mathrm{r}<\mathrm{P}(1)\}$ and $\{\mathrm{P}(1)<\mathrm{r}<\mathrm{P}(2)\}$ are the same as events $\{\mathrm{X}=1\}$ and $\{\mathrm{X}=0\}$. And so the probabilities of variable $r$ falling in three intervals $(0, \mathrm{P}(1))$ and $(\mathrm{P}(1), \mathrm{P}(2))$ are the same as the variable $\mathrm{X}_{\mathrm{D}}$ taking the value of 1 and 0 .

Therefor randomizing the logistics demand enterprises (D)'s strategies can be simulated by sampling $X_{D}$ as the above 3 steps.

Similarly, randoming the third party logistics enterprises (S)'s strategies can be simulated by sampling $X_{S}$ as the above 3 steps.

\section{EXAMPLE OF AN IMAGINARY GAME}

Due to the difficulty of the collecting data and business confidential, this paper could not get all the real number, expect complaint rate, which is from the State Post Bureau of The Peploe's Republic of China.The least complaint rate is 0.08 of Suning. And the highest complaint rate is 43.95 of ZJS express. This paper selects SF express to be the third party logistics and its complaint rate is 3.46 . Thus the $\mathrm{h}$ is 40.49 and $\mathrm{k}$ is 0.923 . Suppose the total investment amount $\mathrm{Q}=8$, the input allocation ration of the logistics demand enterprises (D) and the third party logistics enterprises (S) are respectively $\mathrm{m}=0.7$ and $\mathrm{n}=0.3$. And the total profit $\mathrm{P}=20$, the reward or punishment $\mathrm{b}=6$, cost of the supervision $\mathrm{c}=1$ and leisure income $\mathrm{u}=8$. Thus the principal-agent game of the third party logistics cooperation can be modeled as Table 4.

According to (3) and (6), the logistics demand enterprises (D)'s supervision-indulgence strategy probability of mixed equilibrium is $\left(\mathrm{p}_{1}, \mathrm{p}_{2}\right)=(0.3333,0.6667)$, and the third party logistics enterprises ( $\mathrm{S})$ 's mixed equilibrium is $\left(\mathrm{q}_{1}, \mathrm{q}_{2}\right)=$ (0.4097 0.5903). The average expected payoff of the logistics demand enterprises (D) is shown as (7).

$$
\begin{array}{r}
\mathrm{E}_{\mathrm{D}}=0.3333 \times( \\
\times(0.4097 \times 14.784+0.5903 \times 0.0016)+0.6667 \times(0.4097 \\
\times 21.322+0.5903 \times(-4.5222))=6.0667
\end{array}
$$

And the average expected payoff of the third party logistics enterprises (S) is shown as (8).

$$
\begin{array}{r}
E_{S}=0.4097 \times(0.3333 \times 7.292+0.6667 \times 1.754)+0.5903 \times(0.3333 \times(- \\
0.092)+0.6667 \times 5.446)=3.6
\end{array}
$$

Update the Table 2 and Table 3 by $\left(\mathrm{p}_{1}, \mathrm{p}_{2}\right)=(0.3333$, $0.6667)$ and $\left(\mathrm{q}_{1}, \mathrm{q}_{2}\right)=(0.4097,0.5903)$. According to the three steps method, two simulation programs are written, and simulation of 1000 times is done by Matlab. The random numbers are transmitted to the enterprises, and they select the 
behaviors just mapping 1 and 0 into the supervision or indulgence and positive efforts or negative efforts.

To illustrate the simulation, the histograms of the logistics demand enterprises (D) and the third party logistics enterprises (D) are shown as Figure 1.

From Figure 1, the frequencies of the logistics demand enterprises (D) selecting supervision and indulgence are respectively 345 and 655 . The frequencies of the third party logistics enterprises (S) choosing positive efforts or negative efforts are respectively 400 and 600 . And so, for the simulation of 1000 times, the simulation probabilities of (D) selecting supervision and indulgence are respectively 0.345 and 0.655 . The same as to (S), the probabilities are 0.4 and 0.6. Compared with the theory probabilities $\left(\mathrm{p}_{1}, \mathrm{p}_{2}\right)=(0.3333,0.6667)$ of $(\mathrm{D})$ selecting supervision and indulgence in accordance with mixed strategy equilibrium, the coincidence rate is above $96.52 \%$. Compared with the theory probabilities $\left(\mathrm{q}_{1}, \mathrm{q}_{2}\right)=(0.4097$, 0.5903) of enterprises (S) choosing positive efforts and negative efforts in accordance with mixed strategy equilibrium, the coincidence rate is above $84.8 \%$. Therefore the randomizing coincides with the probability distribution of Nash equilibrium above $84.8 \%$.

In order to visualize the simulation of game, the third party logistics cooperation's game and payoff curves are shown as Figure 2.

TABLE IV. PRINCIPAL-AGENT GAME OF THE THIRD PARTY LOGISTICS

\begin{tabular}{|c|c|c|c|}
\hline \multicolumn{2}{|c|}{ Payoff } & \multicolumn{2}{c|}{ (S) } \\
\cline { 3 - 4 } \multicolumn{2}{|c|}{} & Positive efforts & Negative efforts \\
\hline \multirow{2}{*}{ (D) } & Supervision & $(14.784,7.292)$ & $(0.016,-0.092)$ \\
\cline { 2 - 4 } & Indulgence & $(21.322,1.754)$ & $(-4.522,5.446)$ \\
\hline
\end{tabular}
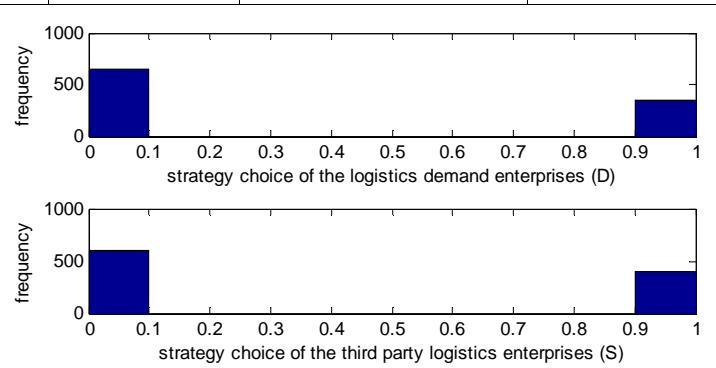

FIGURE I. HISTOGRAM OF ENTERPRISES' RANDOM STRSTEGY CHOICES

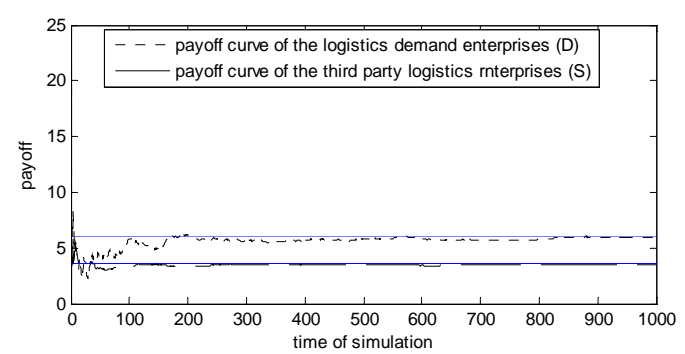

FIGURE II. SIMULATION OF ENTERPRISES' PAYOFF
From Figure 2, it can be seen the average expected payoff of the logistics demand enterprises (D) and the third party logistics enterprises (S) are 6.0667 and 3.6 respectively. The simulation of average expected payoff coincides with the theoretical payoff of mixed Nash equilibrium above $97.18 \%$ 。

Therefore the simulation of random strategies by the method is not only simple but coincides with the theoretical value at high level.

\section{CONCLUSIONS}

To improve the practice feasibility of game theory for the logistics demand enterprises (D) and the third party logistics enterprises (S) in a logistics cooperation, two important works are done. Firstly, principal-agent game of the third party logistics cooperation are estibalished to analyze their mixed Nash strategies and average profits. Secondly Monte Carlo simulation is adopted to randomize the digitalize enterprises' behavior strategies. The simulated probabilities, according to which the strategies are randomized, can be proven theoretically to be consistent with the probabilities of the mixed Nash equilibrium. And the randomizing strategies coincides with the probability distribution of Nash equilibrium above $97.18 \%$.

However, there are still further researches to be done in two aspects. On the one hand, the enterprises should support this with the real business data to make the game perfect. On the other hand, Monte Carlo simulation only generates random sampling data independently. But in pactice the strategies may be affected by each other, so dependent sampling simulations is worth looking forward to ,such as Markov Chain Monte Carlo (MCMC), ect.

\section{ACKNOWLEDGMENT}

Thanks for the funding of Hubei Provincial Department of Education (D20141101) and Hubei Provincial Key Laboratory of Systems Science in Metallurgical Industry (Y201510).

\section{REFERENCES}

[1] B. Neeraja, M. Mehta and A, Chandani. Supply Chain and Logistics For The Present Day business, Proc. Econ. Fin., 2014, pp. 665-675.

[2] J. X. Liu, Enterprise logistics outsourcing in the principal-agent problem and model research, Bus. era, 2007, pp. 17-18.

[3] J. Wang, China's agricultural product logistics e-commerce supply chain network structure and operational mechanism, Acad. For . 2012, pp.132136.

[4] Y. S. Qiao, Third party logistics cooperation relationship game. Chongqing University of Technology master's degree thesis, 2013.

[5] A. Aguezzoul, Third-party logistics selection problem: A literature review on criteria and methods. Omega, 2014, pp.69-78.J.

[6] J. Q. Zhang and Y. Cai, Game theory in the perspective of enterprise commission - agent research, Mod. Bus. Ind., 2009, pp.10-11.

[7] G.S. Fishman, Monte Carlo-Concepts, Alg. Appl., 1996. 